\title{
Clinical profile and comorbidity of traumatic brain injury among younger and older men and women: a brief research notes
}

\author{
Vincy Chan ${ }^{1,2}$, Tatyana Mollayeva ${ }^{1,2^{*}}$, Kenneth J. Ottenbacher ${ }^{3}$ and Angela Colantonio ${ }^{1,2}$
}

\begin{abstract}
Objective: Comorbid disorders influence the course and outcomes of rehabilitation following traumatic brain injury $(\mathrm{TBI})$, yet sex- and age-related disparities in the frequency distribution of these disorders remain poorly understood. We aimed to describe comorbid disorders by the International Classification of Diseases in patients with TBI undergoing inpatient rehabilitation in Ontario, Canada over a 3-year period, by sex and age, and discuss their potential impact on rehabilitation outcomes.

Results: The percentage of TBI patients with one or more comorbid disorder is higher among older ( $\geq 65$ years) men and women than among those who are younger or middle-aged ( $<65$ years). Among younger and middle-aged patients, multiple injuries and trauma, mental health conditions, and nervous system disorders were the most prevalent comorbidities. In older patients, circulatory, endocrine, nutritional, metabolic, and immune disorders were the most prevalent comorbidities. Our results suggest that a multisystem view of rehabilitation of men and women with $\mathrm{TBI}$ across age categories is needed to reflect the complex clinical profile of TBI patients undergoing rehabilitation.
\end{abstract}

Keywords: Traumatic brain injury, Inpatient rehabilitation, Sex, Age, Index disease, Comorbidity, Multimorbidity, Prevalence

\section{Introduction}

Traumatic brain injury (TBI), defined as "a traumatically induced structural injury and/or physiological disruption of brain function as a result of an external force" [1], remains a significant public health issue $[2,3]$. Recent initiatives in TBI care highlight the complexity of its clinical management, and recommend that an assessment of coexisting (comorbid) disorders be included [4]. "Comorbidity" refers to any disease co-existing with an index disease [5]; it can alter the clinical course of patients by affecting selections of healthcare services and outcomes $[6,7]$. While previous population-based research from United States and Canada [8-12] has documented

\footnotetext{
${ }^{*}$ Correspondence: tatyana.mollayeva@utoronto.ca

${ }^{2}$ Rehabilitation Sciences Institute, Faculty of Medicine, University

of Toronto, Toronto, Ontario, Canada

Full list of author information is available at the end of the article
}

comorbidities in TBI, there has been no comprehensive description of sex- and age- specific clinical nosologies for TBI patients entering inpatient rehabilitation. Historically, TBI has been regarded as an injury mostly affecting young males [13]. However, recent epidemiological trends highlight older females being as frequently affected as males, largely as a result of falls [13]. Because many diseases affecting males and females have different frequencies and presentations across their lifespan $[14,15]$, understanding the variability of comorbidity in rehabilitation $[12,14,15]$ will likely lead to a still greater recognition of the unique sex-specific facets of TBI $[16$, 17]. Therefore, the aims of this study were to: (1) describe comorbidity frequencies (along the spectrum of disorders) in younger and older patients, by sex; (2) assess possible sex differences in comorbid disorder frequencies; 
and (3) offer an evidence-based discussion of the clinical relevance of the most frequent comorbidity in TBI.

\section{Main text \\ Methods \\ Participants}

This population-based retrospective cohort study included all patients admitted to inpatient rehabilitation facilities in Ontario, Canada between the fiscal years 2004/05 and 2007/08. Data from all acute care inpatient rehabilitation units and freestanding rehabilitation hospitals were obtained from the National Rehabilitation Reporting System (NRS) [18]. To assess sociodemographic variables, we analyzed primary language (English versus other) and sex (male versus female). The FIM ${ }^{\mathrm{TM}}$ Instrument assessed patients' physical and cognitive ability, with total scores ranging from 18 to 126 , motor scores ranging from 13 to 91 whereas the cognitive scores ranging from 5 to 35 , where lower scores represent 'total dependence' and higher scores 'total independence' [19]. The length of stay (LOS) represents the number of days between admission and discharge, serving as a proxy for injury severity and comorbidity load [18]. Assessed comorbid categories and subcategories are listed in Additional file 1: Appendix S1.

\section{Statistical analysis}

We described continuous data with means and standard deviation, or medians and ranges, and categorical data with frequency counts. Depending on the type of data, we used $t$ tests for binary continuous variables, Chi square tests when analyzing differences between comorbidity categories in both sexes, and the Fisher's exact test when the expected value of any cell of a contingency table was below five. Separate analyses were conducted for younger ( $<65$ years old) and older $(\geq 65$ years old) adults. To address the likelihood of multiple comparison fallacy, we used the Bonferroni method. Two-sided p values of $<0.05$ were considered statistically significant. All analyses were performed using SAS v. 9.1 (SAS Institute, Cary, NC).

\section{Results}

\section{Patient profile}

Table 1 outlines the study population's demographic and clinical data $(\mathrm{n}=1791)$. Of all patients undergoing TBI inpatient rehabilitation, $70.2 \%$ were males. The older patient group's sex distribution was $57.3 \%$ male and $42.7 \%$ female. The mean LOS/median LOS was 49 (SD 50.8)/37 days, and 45 (SD 40.8)/36 days for male and female patients, respectively. LOS differences between sexes in all age categories were non-significant. Male patients had higher total functional scores and motor rating than females at admission and at discharge. When stratified by age, sex differences remained significant in the total functional score at admission $(\mathrm{p}<0.001)$ and discharge $(\mathrm{p}=0.013)$, motor score at admission $(\mathrm{p}<0.001)$ and discharge $(\mathrm{p}=0.002)$, and FIM efficiency $(\mathrm{p}=0.048)$, in younger patients only.

\section{Comorbidities}

Figure 1 presents comorbid conditions by age and sex. A significantly higher proportion of female patients had at least one comorbid disorder at admission and discharge ( $\mathrm{p}<0.001)$ compared to males. When stratified by age, results remained significant only at admission and only in older females $(\mathrm{p}<0.001)$.

The most common comorbidities among male patients, regardless of age, were disorders of multiple injury and trauma (40.6\%), the circulatory system (34.5\%), mental health (31.8\%), and the nervous system (29.8\%). Among female patients, regardless of age, the most common comorbidities related to the circulatory system (50.4\%), multiple injury and trauma (39.7\%), the nervous system (35.0\%), and the musculoskeletal system (32.8\%).

A significantly higher percentage of females than males experienced conditions of the endocrine, nutrition, metabolism, and immune systems $(\mathrm{p}<0.001)$, the circulatory system $(\mathrm{p}<0.001)$, and the musculoskeletal system $(\mathrm{p}<0.001)$.

\section{Results stratified by age}

The most common comorbidities in younger patients of both sexes included multiple injury and trauma (45.9\% male; $47.8 \%$ female); mental health (34.1\%, male; $28.6 \%$ female); and the nervous system (29.0\% male; $33.1 \%$ female). Younger female patients more frequently experienced comorbidities related to symptoms, signs, and illdefined conditions (i.e., chapter 18 of the ICD-10, which includes symptoms, signs, abnormal results of clinical/investigative procedures, and ill-defined conditions regarding which no diagnosis is recorded) compared to males $(\mathrm{p}<0.001)$.

In older patients, circulatory system comorbidities were the most common in both sexes. In older men, comorbidities of the endocrine, nutrition, metabolism, and immune systems (37.6\%); the nervous system (32.0\%); and injury and trauma (27.3\%) were common. Older female patients experienced more frequent comorbid conditions of the musculoskeletal system (45.9\%); and endocrine, nutrition, metabolism, and immune systems (43.7\%). A significantly higher proportion of older females had musculoskeletal conditions compared to older males $(\mathrm{p}<0.001)$. 
Table 1 Descriptive characteristics of TBI patients in inpatient rehabilitation

\begin{tabular}{|c|c|c|c|c|c|c|c|c|c|}
\hline \multirow{2}{*}{$\begin{array}{l}\text { Characteris- } \\
\text { tics }\end{array}$} & \multicolumn{3}{|c|}{ Total $(\mathrm{N}=1791)$} & \multicolumn{3}{|c|}{$0-64$ years $(N=1164)$} & \multicolumn{3}{|c|}{$65+$ years $(N=627)$} \\
\hline & $\begin{array}{l}\text { Males } \\
\mathrm{N}=1257 \\
(70.2 \%)\end{array}$ & $\begin{array}{l}\text { Females } \\
N=534 \\
(29.8 \%)\end{array}$ & p value & $\begin{array}{l}\text { Males } \\
\mathrm{N}=898 \\
(77.1 \%)\end{array}$ & $\begin{array}{l}\text { Females } \\
\mathrm{N}=266 \\
(22.9 \%)\end{array}$ & $p$ value & $\begin{array}{l}\text { Males } \\
\mathrm{N}=359 \\
(57.3 \%)\end{array}$ & $\begin{array}{l}\text { Females } \\
\mathrm{N}=268 \\
(42.7 \%)\end{array}$ & $p$ value \\
\hline \multicolumn{10}{|c|}{ Demographic variables } \\
\hline Age (years) & $50.1 \pm 20.9$ & $59.8 \pm 21.8$ & $<0.001$ & $39.5 \pm 14.3$ & $41.2 \pm 14.4$ & 0.089 & $76.5 \pm 6.7$ & $78.3 \pm 7.2$ & 0.001 \\
\hline $\begin{array}{l}\text { English } \\
\text { language }^{\mathrm{a}}\end{array}$ & $1148(91.3)$ & $486(91.0)$ & 0.828 & $840(93.5)$ & $250(94.0)$ & 0.794 & $308(85.8)$ & $236(88.1)$ & 0.408 \\
\hline \multicolumn{10}{|l|}{ Clinical variables } \\
\hline $\begin{array}{l}\text { 1+ comorbid } \\
\text { condition; } \\
\text { admission }^{\mathrm{a}}\end{array}$ & $1038(82.6)$ & $482(90.3)$ & $<0.001$ & $716(79.7)$ & $226(85.0)$ & 0.057 & $322(89.7)$ & $256(95.5)$ & $<0.001$ \\
\hline $\begin{array}{c}\text { 1+ comorbid } \\
\text { condition; } \\
\text { discharge }^{a}\end{array}$ & $168(13.4)$ & $96(18.0)$ & 0.037 & $105(11.7)$ & $33(12.4)$ & 0.752 & $63(17.6)$ & $63(23.5)$ & 0.066 \\
\hline $\begin{array}{l}\text { Length of stay } \\
\text { (days) }\end{array}$ & $\begin{array}{l}48.8 \pm 50.8 \\
\mathrm{Q}_{2}=37\end{array}$ & $\begin{array}{l}45.4 \pm 40.8 \\
Q_{2}=36\end{array}$ & 0.134 & $\begin{array}{l}54.0 \pm 56.5 \\
\mathrm{Q}_{2}=41.5\end{array}$ & $\begin{array}{l}56.4 \pm 48.5 \\
Q_{2}=45\end{array}$ & 0.490 & $\begin{array}{l}35.9 \pm 28.7 \\
\mathrm{Q}_{2}=31\end{array}$ & $\begin{array}{l}34.5 \pm 27.5 \\
\mathrm{Q}_{2}=28\end{array}$ & 0.530 \\
\hline $\begin{array}{l}\text { Total function } \\
\text { score, FIM } \\
\text { instrument; } \\
\text { admit }\end{array}$ & $\begin{array}{l}83.1 \pm 28.1 \\
Q_{2}=90\end{array}$ & $\begin{array}{l}78.4 \pm 25.9 \\
\mathrm{Q}_{2}=83\end{array}$ & $<0.001$ & $\begin{array}{l}84.9 \pm 29.5 \\
Q_{2}=94\end{array}$ & $\begin{array}{l}79.3 \pm 29.3 \\
Q_{2}=87\end{array}$ & 0.007 & $\begin{array}{l}78.6 \pm 23.5 \\
Q_{2}=83\end{array}$ & $\begin{array}{l}77.4 \pm 22.1 \\
\mathrm{Q}_{2}=80\end{array}$ & 0.510 \\
\hline $\begin{array}{l}\text { Total function } \\
\text { score, FIM }{ }^{\mathrm{TM}} \\
\text { instrument; } \\
\text { discharge }\end{array}$ & $\begin{array}{l}104.2 \pm 24.2 \\
Q_{2}=114\end{array}$ & $\begin{array}{l}101.1 \pm 24.7 \\
Q_{2}=110\end{array}$ & 0.013 & $\begin{array}{l}105.9 \pm 24.5 \\
Q_{2}=116\end{array}$ & $\begin{array}{l}104.1 \pm 25.8 \\
Q_{2}=114\end{array}$ & 0.294 & $\begin{array}{l}99.9 \pm 22.8 \\
Q_{2}=108\end{array}$ & $\begin{array}{l}98.0 \pm 23.0 \\
Q_{2}=106\end{array}$ & 0.314 \\
\hline $\begin{array}{l}\text { Total motor } \\
\text { rating, FIM } \\
\text { instrument; } \\
\text { admit }\end{array}$ & $\begin{array}{l}60.3 \pm 23.8 \\
Q_{2}=65\end{array}$ & $\begin{array}{l}54.9 \pm 21.6 \\
\mathrm{Q}_{2}=56\end{array}$ & $<0.001$ & $\begin{array}{l}62.8 \pm 24.8 \\
Q_{2}=70\end{array}$ & $\begin{array}{l}57.2 \pm 24.4 \\
\mathrm{Q}_{2}=62\end{array}$ & 0.001 & $\begin{array}{l}54.1 \pm 19.6 \\
Q_{2}=56\end{array}$ & $\begin{array}{l}52.6 \pm 18.2 \\
\mathrm{Q}_{2}=53\end{array}$ & 0.338 \\
\hline $\begin{array}{l}\text { Total motor } \\
\text { rating, FIM } \\
\text { instrument; } \\
\text { discharge }\end{array}$ & $\begin{array}{l}77.2 \pm 19.5 \\
Q_{2}=86\end{array}$ & $\begin{array}{l}74.1 \pm 19.6 \\
\mathrm{Q}_{2}=81\end{array}$ & 0.002 & $\begin{array}{l}78.9 \pm 19.7 \\
\mathrm{Q}_{2}=88\end{array}$ & $\begin{array}{l}76.8 \pm 20.6 \\
\mathrm{Q}_{2}=85\end{array}$ & 0.138 & $\begin{array}{l}72.9 \pm 18.2 \\
\mathrm{Q}_{2}=80\end{array}$ & $\begin{array}{l}71.2 \pm 18.1 \\
\mathrm{Q}_{2}=78\end{array}$ & 0.251 \\
\hline $\begin{array}{l}\text { Total cogni- } \\
\text { tive Rating, } \\
\text { FIM }^{\mathrm{TM}} \\
\text { instrument; } \\
\text { admit }\end{array}$ & $\begin{array}{l}22.8 \pm 7.8 \\
\mathrm{Q}_{2}=24\end{array}$ & $\begin{array}{l}23.5 \pm 7.7 \\
\mathrm{Q}_{2}=24\end{array}$ & 0.103 & $\begin{array}{l}22.1 \pm 7.8 \\
\mathrm{Q}_{2}=23\end{array}$ & $\begin{array}{l}22.1 \pm 8.0 \\
\mathrm{Q}_{2}=23\end{array}$ & 0.999 & $\begin{array}{l}24.6 \pm 7.5 \\
\mathrm{Q}_{2}=25\end{array}$ & $\begin{array}{l}24.8 \pm 7.2 \\
\mathrm{Q}_{2}=25\end{array}$ & 0.670 \\
\hline $\begin{array}{l}\text { Total } \\
\text { cognitive } \\
\text { rating, FIM } \\
\text { instrument; } \\
\text { discharge }\end{array}$ & $\begin{array}{l}27.2 \pm 6.7 \\
\mathrm{Q}_{2}=29\end{array}$ & $\begin{array}{l}27.2 \pm 6.8 \\
\mathrm{Q}_{2}=29\end{array}$ & 0.939 & $\begin{array}{l}27.2 \pm 6.7 \\
\mathrm{Q}_{2}=29\end{array}$ & $\begin{array}{l}27.3 \pm 6.8 \\
Q_{2}=29\end{array}$ & 0.839 & $\begin{array}{l}27.1 \pm 6.8 \\
\mathrm{Q}_{2}=28\end{array}$ & $\begin{array}{l}27.1 \pm 6.8 \\
\mathrm{Q}_{2}=29\end{array}$ & 0.967 \\
\hline FIM efficiency & $0.6 \pm 1.0$ & $0.7 \pm 0.9$ & 0.052 & $0.5 \pm 0.9$ & $0.6 \pm 0.6$ & 0.048 & $0.9 \pm 1.0$ & $0.8 \pm 1.1$ & 0.370 \\
\hline
\end{tabular}

Patients with traumatic brain injury in inpatient rehabilitation between 2004/05 and 2007/08 in Ontario, Canada: characteristics by sex and age groups

Values are mean $\pm S D$ or $N(\%)$ unless otherwise specified. T tests, except ${ }^{a}$ Chi squared tests. $\mathrm{Q}_{2}$ indicates the median value

\section{Discussion}

Most previous studies on TBI comorbidity that employed pre-defined checklist or ICD classification codes of comorbid disorders identified increased comorbidity frequencies in TBI patient populations across continuum of care and age [8-12]. Our study's methodological novelty lies in the comparison of population-derived data for each comorbid disorder in TBI by sex within younger and older age categories. Although our results generally confirmed those of earlier reports (high prevalence of cardiovascular pathology [9], psychiatric/behavioural disorders $[8,12]$, musculoskeletal disorders [8], substance use disorders [10-12], etc.), we generated a qualitatively enriched comorbidity profile that includes (1) details on the magnitude of comorbidity prevalence in patients with TBI undergoing rehabilitation, (2) sex differences in the comorbidity across age categories, and (3) specificity of age-dependent comorbidity in TBI. By positioning our results in light of previous research on age- and sex specific comorbidity, we were able to highlight comorbid 


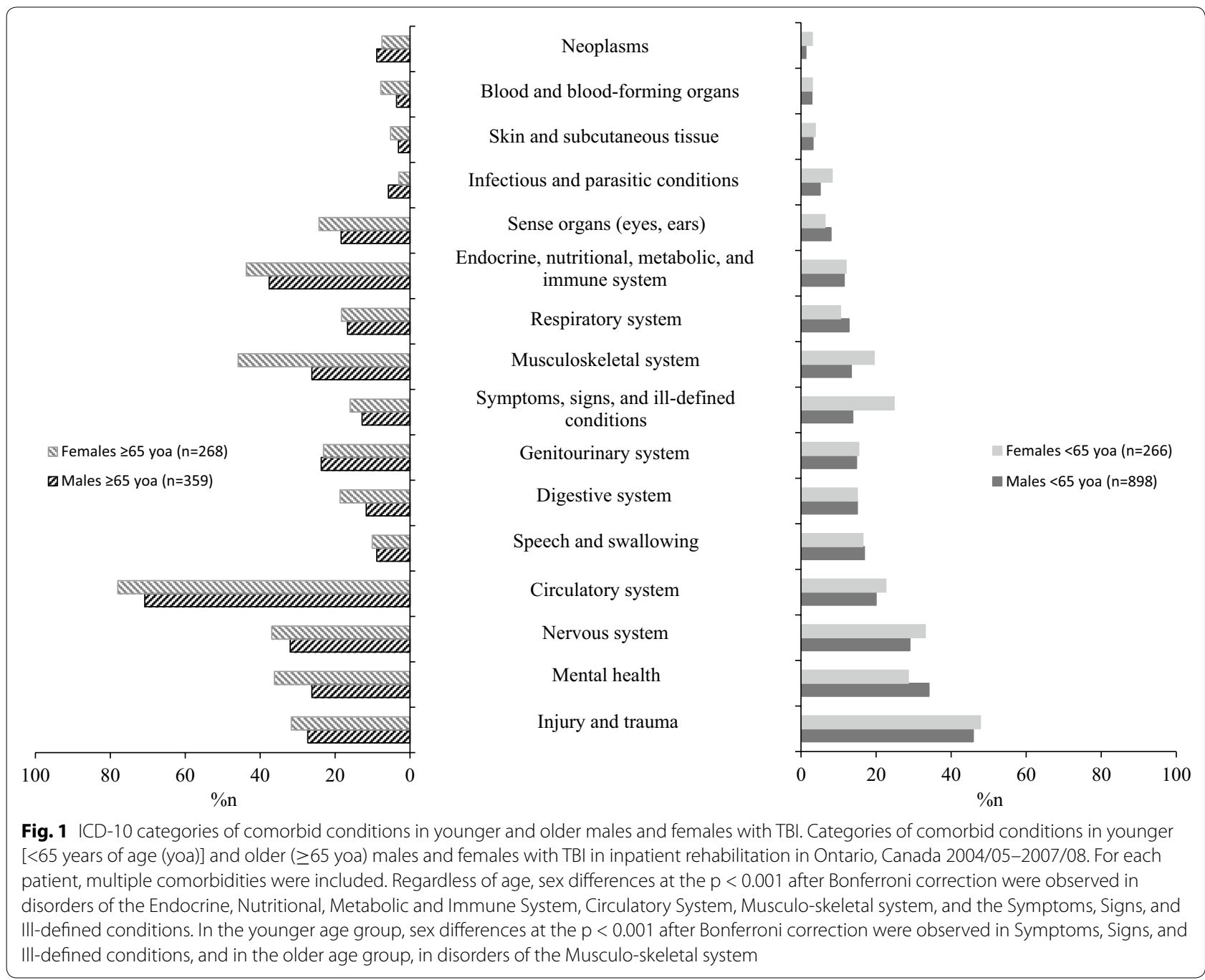

disorders of high relevance to TBI patients undergoing rehabilitation, and shed light on how age and sex may account for the observed results.

Musculoskeletal system comorbidities were observed more frequently in female patients than in male patients, regardless of age. This is unsurprising: osteoarthritis, one of the most commonly occurring disorders within this category, is more prevalent in females [20]. An earlier study reported that $37 \%$ of community-dwelling older adults have arthritis, and the causality of this comorbid condition and TBIs, especially in older women resulted from falls, should be considered [21, 22].

The high frequency of nervous system disorders we observed is consistent with previous studies [5, 8-11]. Chen and colleagues reported an increased stroke risk in individuals with TBI, with a 10-fold higher risk at 3 months post-injury [23]. Because stroke is a highly disabling condition, this relationship demonstrates the need for significant attention and care. Similarly, in a population-based study by Macciocchi and colleagues, $60 \%$ of patients with a traumatic spinal cord injury had a co-occurring TBI [24]. Paraplegic patients with severe TBI had lower FIM $^{\mathrm{TM}}$ motor scores and a longer LOS in rehabilitation, compared to those without TBI or mild TBI [25]. Additional injury to the peripheral nerves occurs in approximately $34 \%$ of patients with severe TBI [26]. As the symptoms of neuropathy are similar to those of the central nervous system disorders, diagnoses and interventions should be assigned with care.

Like reported in earlier studies, mental health disorders are prevalent. In individuals with mild or moderate/severe TBI, an increased prevalence of 34 and $49 \%$ respectively, for any psychiatric condition has been reported during the first year post-injury [27]. Affective disorders are associated with poor functional outcomes [28]. An increased risk of psychosis has been reported in patients with moderate to severe head injuries, with age at injury having no effect on the magnitude of risk [29]. 
Arciniegas and colleagues reported that male patients are at a greater risk of developing psychosis following TBI, compared to females [30]. Psychosis is a potential confounder of TBI diagnosis, and is therefore relevant to rehabilitation.

Circulatory system disorders after brain injury, specifically neurogenic cardiovascular abnormalities, have been linked to increased morbidity and mortality [31]. TBI is reported to trigger biochemical events by altering cerebral blood flow, which has been associated with poorer neurological outcomes [32]. Researchers reported that even mild TBI is associated with the presence and severity of coronary atherosclerosis and predicts cardiovascular mortality independent of age, sex and other risk factors [33]. Therefore, a comprehensive stratification of risk and circulatory system disorder management in TBI patients undergoing inpatient rehabilitation are needed.

Metabolic disorders are more prevalent in older patients compared to their younger counterparts. In a study of patients with moderate to severe TBI, those with diabetes mellitus had a significantly longer hospital stay and higher mortality rate than those without [34]. Clinical malnutrition, a notable comorbidity, has been associated with outcomes following severe TBI 6 months post-injury, independent of the Glasgow Coma Scale score [35]. Neuroendocrine dysfunction is prevalent in approximately two-thirds of people with TBI. Having been shown to result in a complex cascade of pathophysiological and neurochemical events, TBI concerns adversities towards both recovery and stress level, and therefore warrants attention [36, 37]. Disruption of neural connections between the cerebral cortex and the brainstem due to TBI frequently impairs bladder control [38]. This is consistent with the high rate of genitourinary comorbidities in older males and females in our study. Common ill-defined symptoms following TBI involve sleep, pain, apathy, and fatigue, often at higher rates than those observed in the general population [39]. These symptoms can impede rehabilitation by reducing effectiveness and compliance with treatment, and increasing the LOS.

Our study has a number of strengths. Our effort encompassed inclusive adult inpatient population with TBI over a 3-year period. This is the greatest advance over earlier research on the topic of comorbidity, as the NRS includes all data from rehabilitation hospitals from a publicly funded system of care where reporting inpatient rehabilitation data is mandatory. In addition, the use of standardized coding makes our findings more accurate than those based on self-reported data.

In conclusion, our study illustrates that patients have complex comorbidities during rehabilitation, a reality which must be addressed. To develop patient-oriented rehabilitation programs and support clinical decisions, further characterization of comorbidity in TBI in relation to patient-related and system-related outcomes is warranted. In addition, more advanced statistical methodologies that allow modeling of complex interactions of comorbid disorder clusters, starting at the time of injury event, has enormous potential for advancing our understanding of one of the most complex injury, TBI. Finally, because female patients represented a smaller proportion of rehabilitation service users in both younger and older age categories, but more frequently exhibited one or more comorbid disorders in inpatient rehabilitation compared to that of male patients, it is crucial to consider sex inequalities and vulnerabilities when designating resources.

\section{Limitations}

- Information such as acute management of TBI was not available in the NRS; significant limitation because acute care narrates to characteristics of patients entering rehabilitation.

- We utilized the earliest NRS dataset using ICD-10 codes to capture TBI and comorbidity; a future study is planned to determine whether the past decade has seen a change in the frequency distribution of TBI and comorbidity in males and females across age categories.

- We utilized age 65 for defining "old" because of many legislative and healthcare services use this cut-off score; future study should utilize smaller age categories to determine which comorbid disorders are important in the test of age-related hypotheses.

\section{Additional file}

Additional file 1: Appendix S1. Comorbidity categories and corresponding conditions. Comorbidity categories and corresponding conditions by ICD-10 chapter headings.

\section{Authors' contributions}

Study concept and design: all authors. Acquisition of data: VC. Analysis and interpretation of data: all authors. Drafting of the manuscript: TM, VC. Critical revision of the manuscript for important intellectual content: all authors. Statistical analysis: VC. Administrative, technical, and material support: VC. Study supervision: AC, KJO. All authors read and approved the final manuscript.

\section{Author details \\ ${ }^{1}$ Toronto Rehabilitation Institute-University Health Network, Toronto, Ontario, Canada. ${ }^{2}$ Rehabilitation Sciences Institute, Faculty of Medicine, University of Toronto, Toronto, Ontario, Canada. ${ }^{3}$ Division of Rehabilitation Science, Center for Recovery, Physical Activity and Nutrition, School of Health Profes- sions, University of Texas Medical Branch, Galveston, Texas, USA.}

\section{Acknowledgements}

We gratefully acknowledge the contributions of Chen Xiong for his help with editing the manuscript and Shirin Mollayeva for building a figure. 


\section{Competing interests}

The authors declare that they have no competing interests.

\section{Ethics approval and consent to participate}

The Toronto Rehabilitation Institute-University Health Network' (TRI-UHN) Research Ethics Board, approved this study. The study involved analysis of existed health service use database; consent to participate-not applicable.

\section{Consent to publish}

All authors reviewed the final results and agreed the results to be submitted to BMC Research Notes.

\section{Availability of data and materials}

The data is stored at the secure disk at the TRI-UHN. The administrative healthcare dataset that we have used in this study cannot be deposited in publicly available repositories; this reflects the Ministry of Health policy in place to protect the privacy of individual Ontarians and maintain the confidentiality of their information.

\section{Funding}

Research reported in this publication was supported by the Eunice Kennedy Shriver National Institute of Child Health \& Human Development of the National Institutes of Health under Award Number R21HD089106 and the $\mathrm{NIH}$ Research Award 1R21 HD08106-01. The content is solely the responsibility of the authors and does not necessarily represent the official views of the National Institutes of Health.

\section{Publisher's Note}

Springer Nature remains neutral with regard to jurisdictional claims in published maps and institutional affiliations.

Received: 17 April 2017 Accepted: 22 July 2017

Published online: 08 August 2017

\section{References}

1. Brain Injury Association of America. About brain injury. http://www. biausa.org/about-brain-injury.htm. Accessed 14 Feb 2017.

2. World Health Organization. Projections of mortality and burden of disease, 2002-2030: deaths by income group. http://www.who.int/healthinfo/global_burden disease/projections2002/en/. Accessed 14 Feb 2017.

3. World Economic Forum. The global economic burden of non-communicable diseases. 2011. http://www3.weforum.org/docs/WEF_Harvard_HE GlobalEconomicBurdenNonCommunicableDiseases_2011.Pdf. Assessed 31 Jan 2017.

4. Masel BE, DeWitt DS. Traumatic brain injury: a disease process, not an event. J Neurotrauma. 2010;27(8):1529-40.

5. Feinstein AR. The pre-therapeutic classification of co-morbidity in chronic disease. J Chronic Dis. 1970;23:455-68.

6. Young JS, Hobbs JG, Bailes JE. The impact of traumatic brain injury on the aging brain. Curr Psychiatry Rep. 2016;18(9):81.

7. Soo M, Robertson LM, Ali T, Clark LE, Fluck N, Johnston M, Marks A Prescott GJ, Smith WC, Black C. Approaches to ascertaining comorbidity information: validation of routine hospital episode data with clinicianbased case note review. BMC Res Notes. 2014;7(1):253.

8. Gardizi E, Hanks RA, Millis SR, Figueroa MJ. Comorbidity and insurance as predictors of disability following traumatic brain injury. Arch Phys Med Rehabil. 2014;95(12):2396-401.

9. Coronado VG, Thomas KE, Sattin RW, Johnson RL. The CDC traumatic brain injury surveillance system: characteristics of persons aged 65 years and older hospitalized with a TBI. J Head Trauma Rehabil. 2005;20(3):215-28.

10. Kumar RG, Juengst SB, Wang Z, et al. Epidemiology of comorbid conditions among a 50 years and older with traumatic brain injury. J Head Trauma Rehabil. 2017. doi:10.1097/HTR.0000000000000273.

11. Thompson HJ, Dikmen S, Temkin N. Prevalence of comorbidity and its association with traumatic brain injury and outcomes in older adults. Res Gerontol Nurs. 2012;5(1):17-24.
12. Colantonio A, Gerber G, Bayley M, Deber R, Yin J, Kim H. Differential profiles for patients with traumatic and non-traumatic brain injury. J Rehabil Med 2011:43(4):311-5.

13. Leo P, McCrea M. Epidemiology. In: Laskowitz D, Grant G, editors. Translational research in traumatic brain injury. Boca Raton (FL): CRC Press/Taylor and Francis Group; 2016. Chapter 1.

14. Malmusi D, Vives A, Benach J, Borrell C. Gender inequalities in health: exploring the contribution of living conditions in the intersection of social class. Glob Health Act. 2014; eCollection:7(23189).

15. Health Canada. Health portfolio sex and gender-based analysis policy. 2010. http://www.hc-sc.gsc.ca/hl-vs/pubs/women-femmes/sgba-policypolitique-ags-eng.php. Accessed 26 Jan 2017.

16. World Health Organization. Women and health: today's evidence tomorrow's agenda. Geneva: WHO Press; 2009.

17. Armstead WM, Riley J, Vavilala MS. Sex and age differences in epinephrine mechanisms and outcomes after brain Injury. J Neurotrauma. 2017 doi:10.1089/neu.2016.4770

18. Canadian Institute for Health Information. National Rehabilitation Reporting (NRS) Metadata 2012. http://www.cihi.ca/ClHI-ext-portal/internet/ EN/TabbedContent/types+of+care/hospital+care/rehabilitation/ cihi010638\#_Metadata. Assessed 31 Jan 2017.

19. ERABI. Functional independence measures 2011. http://www.abiebr. com/set/17-assessment-outcomes-following-acquiredtraumatic-braininjury/178-functional-independence. Assessed 31 Jan 2017.

20. Feudjo-Tepie M, Ferguson S, Roddam A, Taylor A, Bayly J, Critchlow C. Comorbidities, bone-sparing agent prescription history and their determinants among postmenopausal women in UK primary care settings: a retrospective database study. Arch Osteoporos. 2015;10:41.

21. Asai T, Misu S, Sawa R, Doi T, Yamada M. Multi-chronic musculoskeletal pain is a useful clinical index to predict the risk of falls in older adults with normal motor function. Aging Clin Exp Res. 2015;27(5):711-6.

22. Dragioti $E$, Larsson B, Bernfort $L$, Levin $L \AA \AA$, Gerdle B. Prevalence of different pain categories based on pain spreading on the bodies of older adults in Sweden: a descriptive-level and multilevel association with demographics, comorbidities, medications, and certain lifestyle factors (PainS65+). J Pain Res. 2016;9:1131-41.

23. Chen $\mathrm{YH}$, Kang JH, Lin HC. Patients with traumatic brain injury: populationbased study suggests increased risk of stroke. Stroke. 2011;42(10):2733-9.

24. Macciocchi S, Seel RT, Warchowsky A, Thompson N, Barlow K. Co-occurring traumatic brain injury and acute spinal cord injury rehabilitation outcomes. Arch Phys Med Rehabil. 2012;93(10):1788-94.

25. Esnault $P$, Cardinale $M$, Boret $H$, et al. Blunt cerebrovascular injuries in severe traumatic brain injury: incidence, risk factors, and evolution. J Neurosurg. 2017. doi:10.3171/2016.4.JNS152600.

26. Cartagena LJ, Kang A, Munnangi S, et al. Risk factors associated with in-hospital mortality in elderly patients admitted to a regional trauma center after sustaining a fall. Aging Clin Exp Res. 2016. doi:10.1007/ s40520-016-0579-5.

27. Wang HK, Lin SH, Sung PH, et al. Population based study on patients with traumatic brain injury suggests increased risk of dementia. J Neurol Neurosurg Psychiatry. 2012;83(11):1080-5.

28. Khan F, Amatya B, Judson $R$, et al. Factors associated with long-term functional and psychological outcomes in persons with moderate to severe traumatic brain injury. J Rehabil Med. 2016;48(5):442-8.

29. Chaytor N, Temkin N, Machamer J, Dikmen S. The ecological validity of neuropsychological assessment and the role of depressive symptoms in moderate to severe traumatic brain injury. J Intern Neuropsychol Soc. 2007;13(3):377-85

30. Arciniegas DB, Harris SN, Brousseau KM. Psychosis following traumatic brain injury. Intern Rev Psychiatry. 2003;15(4):328-40.

31. Badaut J, Bix GJ. Vascular neural network phenotypic transformation after traumatic injury: potential role in long-term sequelae. Transl Stroke Res. 2014;5(3):394-406.

32. Larson BE, Stockwell DW, Boas $\mathrm{S}$, et al. Cardiac reactive oxygen species after traumatic brain injury. J Surg Res. 2012;173(2):e73-81.

33. Ahmadi N, Hajsadeghi F, Yehuda R, et al. Traumatic brain injury, coronary atherosclerosis and cardiovascular mortality. Brain Inj. 2015;29(13-14):1635-41.

34. Ley EJ, Srour MK, Clond MA, et al. Diabetic patients with traumatic brain injury: insulin deficiency is associated with increased mortality. J Trauma. 2011:70(5):1141-4. 
35. Dhandapani SS, Manju D, Sharma BS, Mahapatra AK. Clinical malnutrition in severe traumatic brain injury: factors associated and outcome at 6 months. Ind J Neurotrauma. 2007;4:35-9.

36. Munoz A, Urban R. Neuroendocrine consequences of traumatic brain injury. Curr Opin Endocrinol Diabetes Obes. 2013;20(4):354-8.

37. Albert V, Subramanian A, Agrawal D, Bhoi SK, Pallavi P, Mukhopadhayay AK. RANTES levels in peripheral blood, CSF and contused brain tissue as a marker for outcome in traumatic brain injury (TBI) patients. BMC Res Notes. 2017;10(1):139.
38. Kadow BT, Tyagi P, Chermansky CJ. Neurogenic causes of detrusor underactivity. Curr Bladder Dysfunct Rep. 2015;10(4):325-31.

39. Nygren DeBoussard C, Lannsjö M, Stenberg M, Stålnacke BM, Godbolt AK. Behavioural problems in the first year after severe traumatic brain injury: a prospective multicentre study. Clin Rehabil. 2017;31(4):555-66.

\section{Submit your next manuscript to BioMed Central and we will help you at every step:}

- We accept pre-submission inquiries

- Our selector tool helps you to find the most relevant journal

- We provide round the clock customer support

- Convenient online submission

- Thorough peer review

- Inclusion in PubMed and all major indexing services

- Maximum visibility for your research

Submit your manuscript at

www.biomedcentral com/submit 